\title{
Editorial
}

\section{La Revista Pediatría de Atención Primaria da un paso más; ayer, hoy y mañana}

En 1999 nació la Revista Pediatría de Atención Primaria (RPAP) ${ }^{1}$; trece años después hacemos un alto en el camino, intentamos ver el recorrido hecho en perspectiva y estiramos la mirada hacia el horizonte buscando atisbar lo que está por venir. Pero claro, elevar el periscopio sin despegar los pies del suelo no es fácil. Así se puede resumir el momento en el que nos encontramos: un salto hacia delante.

Vamos desde un paradigma en el que el pediatra de Atención Primaria (AP), en su "soledad"2, se nutre de información en soporte papel, que usa y colecciona o desecha, a otro en el que los individuos, como parte de un extenso colectivo, comparten información, conocimiento e incertidumbres, todo ello ubicado, y siempre disponible, en Internet. No es fácil definir, hoy, Internet, por más que convivamos con él y creamos saber qué es; como reflejo de ello, destacar que el diccionario admite escribir esta palabra con mayúscula o minúscula inicial (ya que también es ya un nombre común) y puede, además, acompañarse de adjetivos femeninos o masculinos ${ }^{3}$. Hace no muchos años Internet se nos presentaba como un reto con sus dificultades y sus posibilidades ${ }^{4}$, mientras que hoy es una realidad imprescindible en el trabajo diario ${ }^{5}$ una inmensa fuente de oportunidades por descubrir.

La RPAP ha estado en muchos "lugares". Con el colectivo, tratando de ser protagonistas de su propio desarrollo (Asociación Española de Pediatría de Atención Primaria [AEPap], www.aepap.org) ${ }^{6}$ y atentos al devenir de la organización de la asistencia sanitaria ${ }^{7,8}$; debatiendo sobre docencia ${ }^{9}$ e investigación ${ }^{10,11}$, y en los acontecimientos sociales imposibles de olvidar ${ }^{12}$; promoviendo las actividades preventivas (Prevlnfad ${ }^{13}$ ), la metodología para buscar las mejores pruebas objetivas (Grupo $\mathrm{PBE}^{14}$ ) y recordándonos a los pediatras que debemos mantener los pies en el suelo ${ }^{15}$, el mismo que pisan los niños y familias que atendemos y que debemos estar atentos a los "cantos de sirena" de otros agentes ${ }^{16}$. También, mostrando facetas no científicas sino artísticas relacionadas con niños ${ }^{17}$. Y aspiramos a seguir "viajando".

Un hecho relevante en la historia de la RPAP es la alianza con la AEPap ${ }^{18}$, hecho que simboliza el afán de ambas entidades, del colectivo de pediatras de AP en definitiva, de establecer y ampliar la cooperación y sinergia con otros intereses e interesados. La situación actual de la Pediatría de AP y de las publicaciones médicas en español es crítica; tanto en el sentido de encontrarse ante continuados dilemas e incertidumbres no resueltas, como por el temor que despierta por su futuro. Ya hace unos años, en la RPAP Ilamábamos la atención sobre la necesidad de reflexionar y revisar la trayectoria de la organización sanitaria española ${ }^{19}$. Actualmente, la crisis económica, social y política, que parece de una magnitud extraordinaria, intensifica hasta los límites las dificultades señaladas. 
Mencionábamos en el párrafo anterior las publicaciones médicas en español. Y es que si queremos escribir y leer ciencia en una lengua distinta a la de Shakespeare (además, no en vez de) deberemos resolver las carencias que afectan a la producción y financiación de las propias publicaciones en español ${ }^{20}$. En los últimos años, los costes de edición y distribución de publicaciones en formato papel se han elevado notablemente; $y$, por otro lado, los objetivos de difusión sin fronteras ${ }^{21,22}$ necesitan promover la edición electrónica basada en Internet de las publicaciones. Para la RPAP, el horizonte debe ser, a partir de mañana mismo, además de los pediatras españoles, los que comparten lengua en todos los continentes, especialmente el americano. Y también, otros profesionales interesados en la salud infantil en sus más variadas facetas. Y en financiación de la producción y distribución, el objetivo es la suficiencia e independencia (siendo realista entiéndase esto como menor dependencia, lo cual no es poco) de anunciantes, y, también por qué no, de administradores y gestores públi-

Figura 1. Portada de la Revista Pediatría de Atención Primaria, 1999-2011

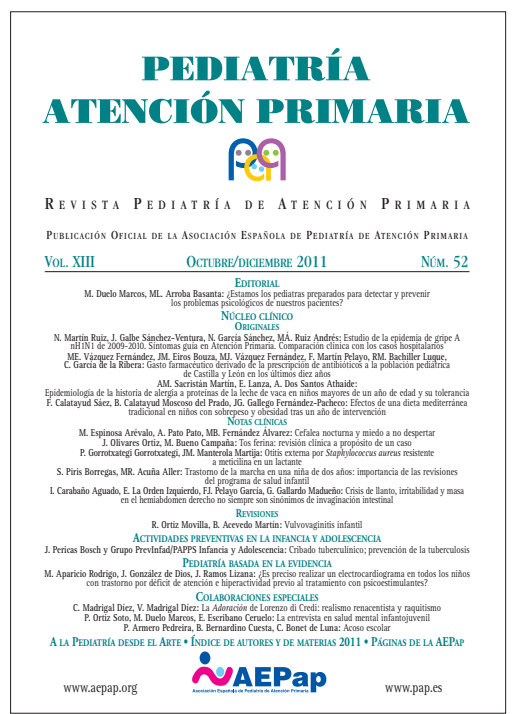

cos, que no siempre interpretan de forma razonable la realidad y las necesidades en salud de la población. Y esto manteniendo la independencia total respecto a los contenidos y revisión de los mismos.

Con este texto hemos querido presentar una panorámica de la historia aún reciente de la RPAP; por eso tanta autocita. Normalmente, esto resulta pretencioso; en este caso las creemos necesarias por el objetivo del texto y deseamos que se interprete solo así; no obstante, nos disculpamos y prometemos no repetirlo hasta, al menos, dentro de otra decena de años.

Para finalizar, destacar dos de los hechos más relevantes de la nueva etapa que ahora comienza: producción y edición a todo color, y la publicación de todos los artículos originales en español e inglés simultáneamente (en inglés solo en la edición web). Y os dejamos las imágenes de la RPAP ayer (Fig. 1) y hoy (Fig. 2).

Figura 2. Portada del número 53 de la Revista Pediatría de Atención Primaria, 2012

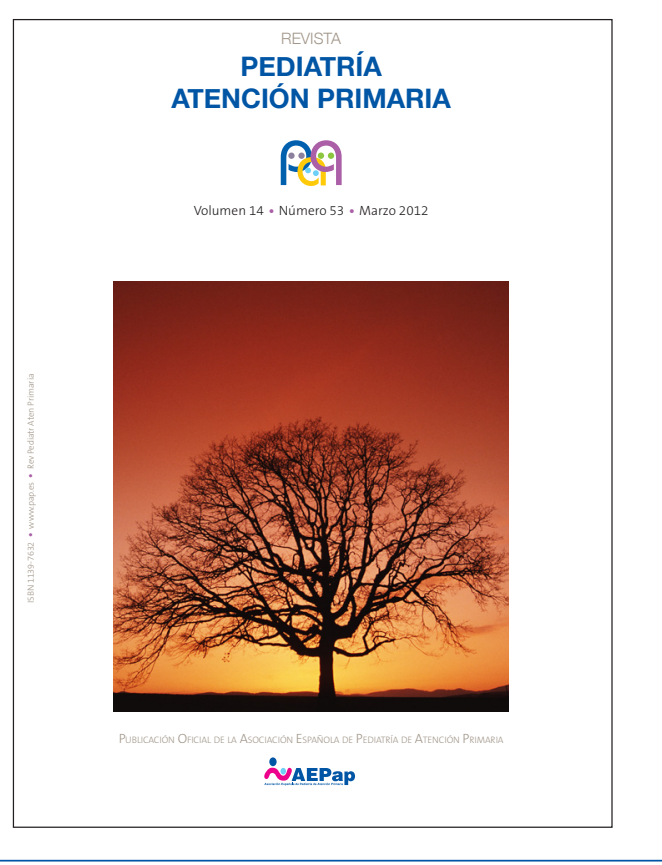




\section{BIBLIOGRAFÍA}

1. Editorial. Pediatría de Atención Primaria, nuestro espacio de reflexión, debate y encuentro. Rev Pediatr Aten Primaria. 1999;1:9-12.

2. Buñuel Álvarez JC. La soledad del pediatra de atención primaria: causas y posibles soluciones. Rev Pediatr Aten Primaria. 1999;1:37-41.

3. Fundéu. Internet [en línea] [consultado el 16/04/2012]. Disponible en www.fundeu.es/vade mecum-l-internet-5107.html

4. Merino Moína M. La informatización de la primaria y los pediatras. Rev Pediatr Aten Primaria. 2000;2:191-7.

5. Internet en la consulta: una necesidad [blog en Internet] [consultado el 15/04/2012]. Disponible en http://internetenlaconsulta.wordpress.com/

6. Editorial. Asociación Española de Pediatría de Atención Primaria (AEPap). Rev Pediatr Aten Primaria. 2000;2:361-4.

7. Domínguez Aurrecoechea B. La pediatría en Atención Primaria después de las transferencias. Rev Pediatr Aten Primaria. 2002;4:377-80.

8. AEPap. El modelo de atención al niño. Rev Pediatr Aten Primaria. 2005;7:549-56.

9. Editorial. Formación continuada. Rev Pediatr Aten Primaria. 1999;1:361-4.

10. Herranz Jordán B. La investigación en Pediatría de Atención Primaria. Rev Pediatr Aten Primaria. 1999;1:533-6.

11. del Castillo Aguas G, Arroba Basanta ML, Buñuel Álvarez JC, Cano Garcinuño A, Gorrotxategi Gorrotxategi PJ, de Inocencio Arocena J. Investigación en pediatría de Atención Primaria: ¿una meta o una ilusión? Rev Pediatr Aten Primaria. 2006;8:203-9.

12. Escribano Ceruelo E. El pediatra de Atención Primaria tras el 11-M. Rev Pediatr Aten Primaria. 2004;6:7-8.

13. Previnfad. [en línea] [consultado el 14/04/2012]. Disponible en http://www.aepap.org/previnfad/ prev-recom.htm

14. Evidencias en Pediatría [en línea] [consultado el 14/04/2012]. Disponible en http://www.evidencias enpediatria.es

15. Bras i Marquillas J. También existe la pediatría de "los niños con una sola cabeza". Rev Pediatr Aten Primaria. 2007;9:15-6.

16. Rodríguez-Salinas Pérez E. La píldora de la eterna juventud no existe, pero ya está a la venta. Rev Pediatr Aten Primaria. 2009;11:379-82.

17. Carabaño Aguado I. ¿Por qué los artistas se interesan por los niños? Rev Pediatr Aten Primaria. 2010;12:11-3.

18. Editorial. Revista Pediatría de Atención Primaria, publicación oficial de AEPap. Rev Pediatr Aten Primaria. 2002;4:561-2.

19. Editorial. 2009: viejos y nuevos retos. Rev Pediatr Aten Primaria. 2009;11:11-6.

20. López JC. El futuro de las publicaciones biomédicas en español. Rev Pediatr Aten Primaria. 2008;10:7117.

21. Buñuel Álvarez JC. Revista Pediatría de Atención Primaria: en camino hacia el acceso abierto. Rev Pediatr Aten Primaria. 2009;11:203-6.

22. San José Montano B. Acceso abierto (open access), un modelo necesario de comunicación científica. Rev Pediatr Aten Primaria. 2009;11:299-311. 